\title{
Pharmacy education in the Sultanate of Oman: Challenges and opportunities
}

\author{
Ahmed A. Abusham ${ }^{1}$ (i), Muna A. Aljuma ${ }^{2}$, Leena A. Ali ${ }^{3}$, Qasim A. Al Riyami ${ }^{4}$, \\ 1 University of Nizwa, Nizwa, Oman \\ ${ }^{3}$ Sultan Qaboos University, Muscat, Oman \\ 2 University of Technology and Applied Sciences, Muscat, Oman \\ ${ }^{4}$ Knowledge Oasis Muscat (KOM), Muscat, Oman
}

\author{
Keywords \\ Curriculum \\ Experiential learning \\ Oman \\ Pharmacy education \\ Pharmacy practice

\section{Correspondence} \\ Ahmed A. Abusham \\ University of Nizwa \\ Nizwa \\ Oman \\ abusham@unizwa.edu.om
}

\begin{abstract}
Pharmacy degree in Oman makes up to 5-year in Bachelor of Pharmacy and 4-year in diploma of pharmacy. The curricula of the pharmacy programme include basic sciences, pharmaceutical sciences, pharmacy practice, and experiential learning. Students are posted in different healthcare sectors and facilities during experiential learning to gain the practice experience. Graduates must complete an internship programme in various healthcare settings, including hospitals, polyclinics, health centres, and community pharmacies. Pharmacists and assistant pharmacists should fulfil the pharmacy licensing conditions and pass the Prometric exam to register and practice pharmacy. There is a shortage of pharmacy workforce in practice, academia, and industry. With the need for a specialised pharmacy workforce in different sectors, it is time to review the pharmacy education in Oman to meet the national needs and priorities.
\end{abstract}

\section{Introduction}

Pharmacy education in the Sultanate of Oman was initiated in 1991 when the Ministry of Health (MoH) established the Oman Assistant Pharmacists' Institute (OAPI) to graduate assistant pharmacists (Diploma in Pharmacy). Presently, there are four Higher Education Institutes (HEIs) offering pharmacy undergraduate degree programmes: The University of Nizwa, National University of Sciences and Technology (previously known as Oman Medical College), Oman College of Health Sciences, and the University of Technology and Applied Sciences (previously known as the Higher College of Technology).

The Sultanate of Oman is one of the Western Asia countries located in the Middle East region. The country is divided into 11 districts known as (Governorate) and Muscat is the capital city of Oman located in Muscat Governorate. Oman's total population was 4.6 million in 2019, as per the Oman National Centre of Statistics and Information (NCSI, 2020). About 31\% of the population lives in the governorate of Muscat. Young adults and children represent $64 \%$ of the Omani population, with children under the age of 5 representing $16 \%$ of the
Omani population. The annual growth rate of the Omani population is $3.5 \%$, and the expected life expectancy is 77 years (NCSI, 2020).

The Sultanate of Oman is classified as a high-incomeeconomy country (WBG, 2019), derived from oil and gas. The health system is funded by the government (78.7\%). The insurance companies (8.2\%) and out-of-pocket spending for direct purchase or cost-sharing (13.1\%) contribute the rest of it (OBG, 2015). The medical service is government-funded and offered freely to all Omani citizens and non-Omanis employed by the government ( $\mathrm{MoH}, 2018)$. Citizens are only required to pay a minor fee for annual registration equivalent to one Omani riyal (OMR) and OMR 0.200 per visit, corresponding to USD 2.6 and USD 0.52, respectively, based on December 2021 exchange rate.

Most of the medications available in Oman must be registered by the Directorate General of Pharmaceutical Affairs \& Drug Control (DGPA\&DC) of the $\mathrm{MoH}$ and subjected to quality-control tests by the same body before being marked in the country. The pharmaceutical industry in Oman is at its developmental stage; the first manufacturing plant was established in 2001. There are 
currently five established pharmaceutical industries manufacturing a selected range of essential generic drugs, and the number of items registered by the DGPA\&DC in 2019 was around 300 (DGPADC, 2019). Examples are The national Pharmaceutical Industries (NPI) in Muscat and Oman and Pharmaceutical Products (OPP) in Salalah. The DGPA\&DC reported that the medicine market in Oman is OMR $80,780,869.651$ in the governmental sector and OMR 95,001,788.338 in the private sector.

The pharmacy profession is rapidly growing in the country, and the policymakers' awareness of its role in improving healthcare is increasing. The number of pharmacists has increased more than three-fold to reach 2692 in 2018 compared to 753 in 2005 . Before 2001 all pharmacists received their training abroad; pharmacy education is at a development stage in Oman, resulting in limited academic research in pharmacy practice or pharmaceutical sciences. Community pharmacy serves the private healthcare sector, as all the prescriptions from government-owned healthcare facilities are dispensed free of charge within pharmacies located in those facilities. The 2018 annual health report published by the $\mathrm{MoH}$ showed 2692 pharmacists and 1998 assistant pharmacists in Oman, representing 5.57 pharmacists and 4.2 assistant pharmacists for every 10,000 of the population, respectively. However, only $30 \%$ of pharmacists work in the government sector, compared to $70 \%$ in the private sector. Also, two-thirds of the assistant pharmacists work in the government sector compared to one-third in private. The national pharmacy workforce supply is growing steadily, and it stands for almost $50 \%$ of the total pharmacy workforce by 2019 (MoH, 2018).

With the population growth and expansion of healthcare services, the demand for the national pharmacy workforce to support the other healthcare teams in providing clinical services and patient care has significantly increased. Consequently, pharmacy schools in the country are expanding to fulfil the practice needs.

This review article discusses pharmacy education in Oman, illustrating the evolution of pharmacy education and practice in the last few decades. It will discuss the current challenges and future opportunities for pharmacy education in Oman. Furthermore, it will provide insight into pharmacy education in Oman and move forward to support the pharmacy practice and industry with a competent pharmacy workforce.

\section{Pharmacy programmes in Oman}

Pharmacy education in the Sultanate of Oman has evolved over the years. Before the 1990s, there was no pharmacy school in the country, and the national pharmacy workforce had to obtain their pharmacy degree from overseas universities. Presently, many public and private institutes offer pharmacy degrees. The first institute was established by the $\mathrm{MoH}$ in 1991 and offered a diploma in pharmacy. This programme was upgraded into a Bachelor of Pharmacy (BSc.) in 2015 $(\mathrm{MoH}, 2018)$. The institute name has been changed to Oman College of Health Sciences (OCHS). Another public institution that offers a diploma in pharmacy is the Pharmacy Department at the Higher College of Technology - UTAS, which was established in 2003. The first private school of pharmacy that offered a BSc. degree was established in 2003 by Oman Medical College in academic partnership with West Virginia University. The college is known today as NUST (NUST, 2020), followed by the University of Nizwa, which was established in 2004 and had two levels: BS. and a diploma in pharmacy. Table I summarises the pharmacy programmes available at the four institutes.

Most schools apply the semester education system. All government schools of pharmacy offer a full scholarship to Omani nationals. The data on annual student intakes (presented in Table I) is the number of seats offered as a government-sponsored scholarship for Omani citizens. Data on actual information for private universities (including self-funded) is not available, noting that more than $68 \%$ of pharmacy students at the University of Nizwa are non- Omani (UN, 2020). Data on the nationality of pharmacy students at the National University is not available. The duration of pharmacy degree study, excluding the foundation year, is a 4-year diploma or a 5-year BSc. degree. To date, no university in Oman offers a Doctor of Pharmacy (Pharm.D.) programme.

Pharmacy schools in the country offer limited postgraduate pharmacy courses. Sultan Qaboos University (SQU), a public university in the country, is offering an MSc in Clinical Pharmacy, and recently a doctoral degree, under the supervision of the Department of Pharmacology and Clinical Pharmacy of the College of Medicine and Health Sciences. The Pharmacy Department of SQU Hospital provides a training site for these students. (SQU, 2020a). However, this limited intake that does not exceed eight students for MSc and two students for the Ph.D. (no published reference is available) necessitates Omani pharmacy graduates to pursue higher pharmacy education and training in universities abroad, e.g., the GCC, Europe, North America, and Australia, through government scholarships. Recently the College of Pharmacy in NUST has been approved to start an MSc Clinical Pharmacy programme and is expected to have the first intake in February 2022 with ten students per intake (NUST, 2021). 
Table I: Pharmacy programmes offered by Omani universities in the year 2020

\begin{tabular}{|c|c|c|c|c|c|}
\hline University & $\begin{array}{l}\text { Pharmacy } \\
\text { programme }\end{array}$ & $\begin{array}{c}\text { Programme } \\
\text { started } \\
\text { (Year) }\end{array}$ & $\begin{array}{l}\text { Institutional } \\
\text { system }\end{array}$ & $\begin{array}{c}\text { Study } \\
\text { duration } \\
\text { (Year) }\end{array}$ & Annual student Intake ${ }^{\S}$ \\
\hline \multicolumn{6}{|l|}{ Public Higher Education institute } \\
\hline \multirow[t]{2}{*}{ Sultan Qaboos University (SQU) } & MSc. & 2004 & Semesters & 2 & $5-8$ \\
\hline & PhD & 2012 & & 4 & $1-2$ \\
\hline \multirow[t]{2}{*}{ Oman College of Health Sciences (OCHS) } & Diploma* & 1991 & Year/cohort & 2.5 & 50 \\
\hline & BSc. & 2016 & & 4 & 50 \\
\hline $\begin{array}{l}\text { The University of Technology and Applied } \\
\text { Sciences (UTAS) }\end{array}$ & Diploma & 2003 & Semesters & 3 & 25 \\
\hline \multicolumn{6}{|l|}{ Private Higher Education Institute } \\
\hline \multirow[t]{2}{*}{ University of Nizwa (UN) } & Diploma BSc. & 2004 & Semesters & 5 & $40-60$ \\
\hline & & & & 4 & \\
\hline National University of Sciences and & BSc. & 2003 & Semesters & 4 & $20-50$ \\
\hline \multirow[t]{2}{*}{ Technology (NUST) } & MSc. & 2020 & & 2 (full-time) & 10 \\
\hline & & & & $\begin{array}{l}3 \text { (Part- } \\
\text { time) }\end{array}$ & \\
\hline
\end{tabular}

${ }^{*}$ Diploma programme suspended in 2016

${ }^{\S}$ Actual intake data not available; numbers reflect the governmental scholarship seats offered by the Higher Education Admission Centre

All pharmacy programmes are reviewed by the $\mathrm{MoH}$ and approved by the Ministry of Higher Education, Research, and Innovation. The Oman Academic Accreditation Authority and Quality Assurance of Education (OAAA) is the authorised accreditation body for all universities (OAAA, 2020). Furthermore, the school of pharmacy at the University of Nizwa is the first school to start the negotiation process seeking international accreditation provided by the Accreditation Council for Pharmacy Education (ACPE) (ACPE, 2021). OAAA has recently piloted and issued the Oman qualification framework, which identified four pathways for higher education: professional, academic, technological, and vocational. This framework, which sets out the national requirements of all the qualifications offered in the country, will assist in reviewing the current and future pharmacy programmes in Oman to ensure it meets the specification set (OAAA, 2019). In Indonesia, the Pharmacy programmes are classified as undergraduate, professional, or vocational following the specifications set by the Indonesian Qualification Framework (Cokro et al., 2021).

\section{Entry requirements}

Students who wish to join the pharmacy programme must complete the 12 years of secondary school and pass the General Education Diploma. The Higher Education Admission Centre (HEAC) regulates the selection criterion for entering the pharmacy programme. To be accepted in the diploma programme, a student must score an overall average of at least C (60\%) and pass science subjects, including biology and chemistry. The required score for the BSc. programme is at least $65 \%$ for the same courses (HEAC, 2021). English proficiency of at least 500 TOEFL or 5.5 ILETS is also a requirement. Bridging students (those with a diploma in pharmacy working as assistant pharmacists, who wish to become pharmacists) can apply for the BSc. programme and will be admitted after equating their diploma transcript with the BSc. programme entry requirement. All students are required to complete a foundation year, covering English, IT, and Math courses, before entering the pharmacy programme.

Entry to a postgraduate programme in pharmacy requires a BSc. with a cumulative GPA of not less than 2.75 , with two years or more of work experience, English proficiency of at least 550 (69) in TOEFL or 5.5 ILETS for the MSc programme. In the Ph.D. programme, the English score should be at least 600 in international TOEFL or 6.5 ILETS (SQU, 2020b; NUST, 2021; SQU, 2021).

Figure 1 below illustrates the number of seats granted by the Higher Education Admission Centre (HEAC)to Omanis for pharmacy education in the last five years. The data for the diploma in pharmacy is provided by UTAS only. At the same time, BSc. data represents admissions in $\mathrm{MoH}$ College of Pharmacy, National University of Science and Technology, and Nizwa University, in addition to a few (5-7 seats) international scholarships. In the last two academic years, 2019-2020 and 2020-2021, the seats offered were 98 for BSc. and only 25 for a diploma in pharmacy. 


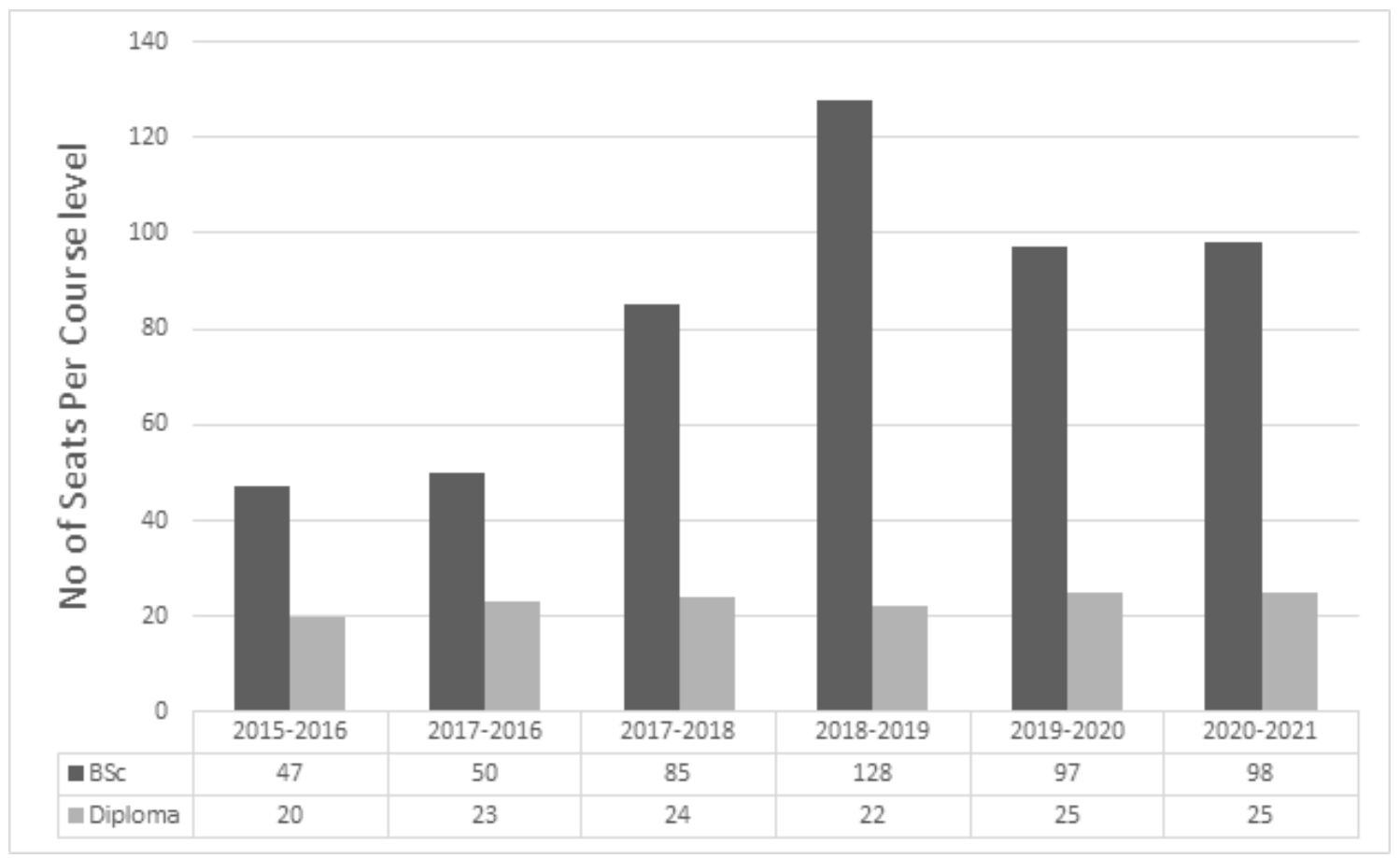

Figure 1: Numbers of seats offered for each pharmacy programme by the HEAC (HEAC, 2021)

\section{Pharmacy curriculum}

The pharmacy curriculum is outcome-based. The main components are fundamental sciences and pharmaceutical sciences, including pharmaceutics, pharmacology, physical pharmacy, pharmacy practice, applied therapeutics, and pharmacotherapy. Typically, pharmacy school departments include pharmacology, pharmaceutics, medicinal chemistry, pharmacy practice and experiential learning. The curriculum focuses on the pharmacist's role in the clinical setup and dispensing of prescriptions (UN, 2018a; NUST, 2020; UTAS, 2020). Table II summarises the introductory and pharmaceutical courses covered in undergraduate pharmacy programmes.

The diploma in pharmacy is the entry point to practice pharmacy in Oman, although people with this degree practise under direct supervision. Their role could be equated to the professionally trained pharmacy technicians in most developed countries, such as Canada and the USA. These assistant pharmacists study comprehensive academic courses and training in pharmacology, pharmaceutics, numeracy, law, and regulations governing pharmacy practice.

Courses covered in the BSc. programme include fundamental sciences like anatomy, chemistry, biology, mathematics, physiology, pathology, pharmaceutical chemistry, pharmacology, botany, and pharmacognosy. These courses are followed by more applied and discipline-specific topics, such as physical chemistry, applied pharmacokinetics, pharmaceutics, drug discovery and formulations, pharmacoepidemiology, and pharmacotherapy (Table II). The first-year pharmacy courses cover university and college requirements like the English language, communication skills, entrepreneurship, Omani history and culture, and fundamental biomedical sciences, including anatomy, physiology, and pathology. Second- and third-year students start intensive pharmacy coursework in pharmacology, pharmaceutics, medicinal plants or pharmacognosy, public health, and pharmacy law. In the fourth-year, courses include pharmaceutical chemistry and pharmacy practice management. The fifth-year courses include pharmacoepidemiology, pharmacoeconomics, and pharmacotherapy of comorbidities using evidence-based practice and critical literature evaluation. Every student must carry out a graduation project under the supervision of a faculty. This graduation project introduces students to research techniques, literature search, reporting of results, and oral presentation of findings. Students may register for elective courses at any time during the last study year. (UN, 2018b).

Fifth-year students proceed for an internship course, an advanced experiential learning programme, upon successful completion. They rotate at pharmacy departments of primary and secondary hospitals and community pharmacies. After satisfactory completion of the required courses and internship, students at the School of Pharmacy of the University of Nizwa must go through another set of assessments called Pharmacy Professional Examination (PPE). The professional examination has three components, i.e., multiplechoice questions (MCQs), Objective Structured 
(Simulated) Clinical Examination (OSCE) and oral examination. Four weeks before the PPE, review classes are conducted to prepare candidates for the examination. The review class and the PPE help the students in their Prometric Examination conducted by Oman $\mathrm{MoH}$.

The MSc. in clinical pharmacy is a two-year (four semesters) full-time programme offered by SQU and NUST. The latter allows part-time study, extending to three years (six semesters). Students who join the MSc. programme will study research methodology, communication skills, literature evaluation, applied pharmacokinetics, and applied therapeutics, in addition to one or two elective courses such as critical care medicine, pharmacogenomics, parenteral nutrition, or pharmacovigilance. Students in clinical rotation must attend clinical rounds in the attached teaching hospital and are evaluated by the clinical pharmacists responsible for their training. The second year comprises clinical research and thesis writing. It typically includes two research seminars before thesis defence (SQU, 2020a; NUST, 2021).

The only available Ph.D. programme in Oman for pharmacy is PhD in Clinical Pharmacy by the Department of Pharmacology and Clinical Pharmacy of the College of Medicine and Health Sciences at SQU (SQU, 2021). In this 4-year programme, candidates are expected to produce a thesis in an area of pharmacy practice and develop their skills as independent researchers.

Table II: The typical curriculum in pharmacy schools in Oman

\begin{tabular}{|c|c|c|}
\hline Learning & Curriculum courses BSc. & Curriculum courses Diploma \\
\hline Basic sciences & $\begin{array}{l}\text { Biostatistics and Computer Applications, } \\
\text { Fundamental of Chemistry, General Biology, Organic chemistry, } \\
\text { Analytical Chemistry, Biochemistry, } \\
\text { Health Communication and Education skills, } \\
\text { Anatomy, Physiology, Pathophysiology } \\
\text { Microbiology and Immunology, } \\
\text { Botany. }\end{array}$ & $\begin{array}{l}\text { Pharmaceutical Terminology, First Aid, } \\
\text { Fundamental of Chemistry, Biochemistry, } \\
\text { Microbiology, Pharmacognosy, public } \\
\text { health. }\end{array}$ \\
\hline $\begin{array}{l}\text { Pharmaceutical } \\
\text { sciences }\end{array}$ & $\begin{array}{l}\text { Pharmacognosy and complementary medicine, Pharmaceutical } \\
\text { Chemistry, Pharmaceutics, Physical Pharmacy } \\
\text { Practice Management and Health Care Systems } \\
\text { Social and Behavioral aspects of Pharmacy Practice } \\
\text { Pharmacy Law and regulations, } \\
\text { Pharmacology, Toxicology, } \\
\text { Clinical Pharmacy, Clinical Pharmacokinetics, Pharmaceutical } \\
\text { biotechnology, } \\
\text { Pharmacotherapy, Pharmacogenetics, and Pharmacoepidemiology }\end{array}$ & $\begin{array}{l}\text { Pharmaceutical Chemistry, Pharmaceutics, } \\
\text { Pharmacy Practice, Pharmacy Laws and } \\
\text { management Pharmacology, Applied } \\
\text { Therapeutics, Quality Control, Medicinal } \\
\text { Chemistry, }\end{array}$ \\
\hline Electives & $\begin{array}{l}\text { Man and the environment, } \\
\text { Introduction. to psychology, } \\
\text { Introduction to economics, } \\
\text { Advanced Instrumental Analysis, } \\
\text { Advanced Clinical Chemistry. }\end{array}$ & $\begin{array}{l}\text { Public speaking and communication skills, } \\
\text { Technical Writing, English for Pharmacy, } \\
\text { Entrepreneurship }\end{array}$ \\
\hline $\begin{array}{l}\text { Experiential } \\
\text { education }\end{array}$ & $\begin{array}{l}\text { Practicums: Hospital and private pharmacy placement, } \\
\text { Clinical Pharmacy Placement, } \\
\text { Internship rotations ( } 12 \text { credit hours/650 contact hours) } \\
\text { Pharmacy Professional Review (OSCE) }\end{array}$ & $\begin{array}{l}\text { Departmental Pharmacy Training (DPT), on- } \\
\text { job-training (OJT): attachment and rotation }\end{array}$ \\
\hline
\end{tabular}

\section{Experiential education}

All pharmacy programmes in Oman have experiential learning components. Students are mandated to do practicums and internship rotations in pharmacy departments of governmental hospitals, polyclinics, and health centres, in addition to community pharmacies and the pharmaceutical industry (Table II). Experiential training takes place at training sites and is supervised by experienced preceptors. Preceptors must be experienced registered pharmacists who have been trained by the respective school. Pharmacy schools provide training in supervision and assessment to preceptors before assigning their students to the training sites.

Practicums represent introductory placements where students are exposed to various professional activities. All schools introduce their students to practicum starting the third semester of the programme for different durations. Throughout the pharmacy programme, practicums comprise at least 11 credits (512 contact hours). The advanced experiential learning experience (internship) is a 500-600-hour 
training programme. Students rotate in the pharmacy departments of government-owned hospitals, polyclinics, primary health centres, and community pharmacies. Students work independently yet under the supervision of their assigned preceptors. Three main types of assessment are carried out in experiential placements, i.e., training logbooks/portfolios, preceptor evaluation, and oral presentation (UN, 2018b).

\section{Requirements to practise pharmacy in Oman}

To be registered as a pharmacist or assistant pharmacist, a graduate must fulfil the licensing conditions to practise in the country: obtaining the BSc. or equivalent (diploma in pharmacy for assistant pharmacist), successful completion of internship rotations, and passing the Prometric (licensing) examination conducted by the Oman Medical Specialty Board (OMSB) (DGPADC, 2020; OMSB, 2021). The registration is organised and facilitated by the Pharmacy Board at the MoH. Candidates must pass a written Prometric exam and an oral examination before registering as a practising pharmacist or assistant pharmacist. The number of pharmacists and assistant pharmacists who applied for licensing assessments in 2019 was 360, out of whom 171 has passed (DGPADC, 2019). The OMSB has started to review the licensing examination of all healthcare specialisations. This review aims to develop a national competency-based licensing assessment, thus allowing the pharmacy schools to benchmark their pharmacy programmes against the competencies required for their graduates to practise in the country.

\section{Current pharmacy practice and career opportunities}

Registered pharmacists and assistant pharmacists are eligible to practise pharmacy in different settings: hospitals, primary care, and community pharmacy. However, only registered pharmacists are allowed in industry or regulatory affairs. Both professions have the same roles and responsibilities, except for some legal requirements, where assistant pharmacists work under the supervision of pharmacists and are not allowed to handle controlled medicines.

Hospital pharmacy is the principal area of interest for the national pharmacy workforce, followed by community pharmacy and industry (Kheir et al., 2008). A respectable number of these pharmacists are employed either in government hospitals or community pharmacies. The reported available pharmacies in Oman are 734 public (community) pharmacies, 54 in-house pharmacies, 96 drugstores, and five drug manufacturing industries (DGPADC, 2019). Some pharmacy graduates prefer to stay at home or work transiently in a community pharmacy, awaiting being employed in the government for the previously mentioned reasons. The industry only employs a few pharmacists as the number of drug manufacturing plants in Oman is limited.

In hospital pharmacies, the pharmacy workforce reviews prescriptions and dispenses medicines, following the standards for picking, labelling, and delivering the treatment while counselling patients in dedicated counselling rooms. Hospital pharmacists also provide drug information services to healthcare professionals. Assistant pharmacists usually perform stock control and topping-up or unit-dose system. They also prepare IV admixtures, total parenteral nutrition, and reconstitute cytotoxic medications using laminar flow hoods under the supervision of pharmacists. New pharmacists gradually acquire knowledge and skills to develop as specialised pharmacists in these areas. Clinical pharmacists have a relevant postgraduate qualification, mostly clinical pharmacy, from the United Kingdom, Australia, or Sultan Qaboos University in Oman. These pharmacists practise in different medical wards, including nephrology, ICU, oncology, paediatrics, and infectious disease units. Few Omani pharmacists hold a Ph.D. in pharmaceutical sciences; they fill either managerial or academic positions in the government. Furthermore, limited pharmacists specialise in newly emerging pharmacy specialities like radio, nuclear, or genomic pharmacy.

Community pharmacies are considered small businesses, with some exceptions. Most of these pharmacies are managed by expatriates. Omani pharmacists prefer to work in the $\mathrm{MoH}$ and government hospitals because of the better remuneration and the less working time. Any registered Omani pharmacist can establish their community pharmacy after fulfilling the $\mathrm{MoH}$ requirements. The $\mathrm{MoH}$ published the Oman National Formulary, the official reference of prescription and non-prescription medicines and the accepted prescription abbreviations. Medications are usually ordered monthly from drug companies/stores. Those about to expire are redistributed to other pharmacies or returned to drug companies three months before expiry. In community practice, the main activity is the dispensing of prescriptions and over the counter (OTC) medications, in addition to patient counselling. A pharmacist must manage a community pharmacy.

The pharmacy law updated recently explicitly states the role of Omani pharmacists in other pharmacy-related sectors such as pharmaceutical companies, industry, scientific offices, and research, which is expected to attract the national pharmacy workforce to fill work positions other than clinical pharmacists, such as 
medication safety officer, regulatory affairs, or pharmaceutical representative $(\mathrm{MoH}, 2020)$.

\section{Challenges of pharmacy education in Oman}

While acknowledging the need to advance pharmacy education in Oman, this review addresses the main challenges. There is a shortfall of pharmacy academics with the specialised qualifications necessary for effective teaching and developing pharmacy education in Oman. Moreover, there is limited infrastructure and limited access to teaching and learning resources, research capacity, and funding. All these factors will slow the advancement of education to meet future practice needs.

The shortage of pharmacy workforce in the country to meet the demand for advanced and specialised care is one of the challenges faced by pharmacy practice. Vision 2 of the Oman Health vision 2050 "Human resources for health developed to sustain the health system" (MoH, 2014), aiming to overcome the main challenges: (1) to provide a sufficient ratio of healthcare professionals per capita, benchmarked with the international ratio of high-income countries; and (2) to increase the number of specialised healthcare professionals to provide advanced and specialised care that is accessible to all the community. Hence, this will require increasing the number of intakes to meet the country demand for pharmacy graduates and reviewing the pharmacy curriculum to meet future needs.

Another challenge will be attaining practical and adequate experience and training by the graduate pre and postgraduation. With the expanding number of pharmacy schools and increased student intake, training facilities are not enough to accommodate all students. Pharmacy schools prefer to carry out the training in government hospitals to ensure that the graduate receives appropriate and quality clinical training. The role of pharmacists in pharmaceutical care and patient-centred care is more developed in these settings than in private hospitals and community pharmacies. Thus, it is expected to obtain the necessary clinical experience in this sector. This challenge is common in the Arab world practice, where the availability of educators or preceptors to train the graduates are limited in the region (Aljadhey, 2013; AlGhananeem et al., 2018)

Health qualifications should be need-based and competency-based that fit for purpose. Pharmacy schools in Oman follow the traditional education of pharmaceutical sciences. The teaching varies among national schools, and the academic research is limited (Obaid et al., 2021). The OSCE and interprofessional education is not well structured or fully implemented in pharmacy schools in Oman (El-Awaisi et al., 2016; AlGhananeem et al., 2018). Although pharmaceutical care and patient-centred care are practised and implemented in hospital settings, it is almost absent in private healthcare, including community pharmacies. The new pharmacy law made the counselling area mandatory in all private community pharmacies to emphasise the importance of patient counselling and improve patient care. In general, patient-centred care activities in community pharmacies represent a challenge because the social and economic forces usually overtake professional obligations (Resnik et al., 2000). With the need to advance the healthcare system in Oman and achieve the Oman Health 2050 visions, pharmacy practice should be patient-centred and not product-oriented, pharmacy workforce to be an active part of the multi-professional healthcare team, and enhance the competency of pharmacy graduates to advance the healthcare services. The vision expects to graduate a clinically-oriented pharmacy workforce with M.Pharm. or Pharm.D. degrees. Many countries worldwide and in the Middle East started to offer a Pharm.D. programme, and some made it mandatory in all pharmacy schools (Anderson \& Futter, 2009; Chanakit et al., 2014; Supapaan et al., 2019).

Furthermore, Continuing Professional Development (CPD) programmes are well established by the pharmacy workforce working in the governmental healthcare sector (FIP, 2014). However, they are limited and do not meet the need of a pharmacy workforce working in private healthcare sectors. Although the CPD regulated by the OMSB was introduced for all healthcare professionals in 2004, it remains non-mandatory in most Arab countries (AlGhananeem et al., 2018). English language proficiency, cultural behaviour, the lack of critical thinking among many student pharmacists are additional challenges of pharmacy education in Oman, from the authors' observation.

\section{Opportunities and future of pharmacy education}

The pharmacy sector is at its early stage of development in Oman. The role of the pharmacy profession is starting to be recognised in different sectors, including clinical settings, industry, regulatory affairs, and academia. There is an enormous opportunity to enhance the pharmacy workforce education and training in Oman to meet the need of practice. During the COVID-19 pandemic, many countries allowed qualified pharmacists to support the healthcare system to ensure the continuity of care 
(Ahmad et al., 2020; Maidment et al., 2021). For example, pharmacists were actively involved in the COVID-19 vaccination campaign in the countries that trained and allowed pharmacists to provide vaccination services.

There is a need to advance both undergraduate and postgraduate education in Oman to achieve the Oman health vision for specialised healthcare and overcome the shortage of specialised pharmacy workforce in different sectors. The neighbour GCC countries have approved and implemented the Pharm.D. programme to meet the demand and need for clinical pharmacists. With the expanding role of pharmacists in other sectors, other postgraduate studies related to pharmacoeconomics, pharmaceutics, drug formulation, medicinal plants, pharmacology, pharmacogenomics, and pharmacovigilance should be introduced to meet the market needs in research and academia. Building the capacities for the future demand of preceptors will be essential to enhance experiential education in all patient care settings.

Curricula must support patient-centred and multiprofessional healthcare integrated education to produce a graduate competent enough to contribute to direct patient care in all settings. There is a need for pharmacy educators and leaders to commit to patientcentred care philosophy. The curricula offered should be thoroughly reviewed to put up more clinical practice and experiential learning to enhance the competency of pharmacists. Relevant national stakeholders, such as policymakers, academics, and industry, should work together to set the standards and strengthen the curricula to meet the need of future practice. A national framework for components such as interprofessional education, pharmacovigilance, and medication safety should be available for the national universities that offer medical and health professional studies (WHO, 2010; El-Awaisi et al., 2017; Al-Ghananeem et al., 2018; van Eekeren et al., 2018; Alghamdi et al., 2021).

In addition to the need for a clinically specialised pharmacy workforce, there is also a demand for the pharmacy workforce to practise in the industry and regulatory settings. International organisations, such as the FIP, set goals and strategies to enhance pharmacy practice and education worldwide (FIP, 2008; FIP, 2020). The 12 developmental goals enhance the pharmacy workforce competency and education while providing a framework to systematically assess the needs based on the country vision and priorities. The educators in Oman, therefore, should collaborate and work together along with the professional leaders, stakeholders, and policymakers to set the national development goals for a competency-based pharmacy education that meets the country needs, priorities, resources, and culture (Anderson \& Futter, 2009; Nasr \& Wilby, 2017). Collaborating with regional and international pharmacy schools and organisations to achieve an international standard and accreditation in pharmacy education and practice will also contribute effectively to WHO and FIP strategy for universal health and improved patient care (FIP, 2020). Introducing the population health beliefs, especially to understand the patient inclination towards the use of complementary medical practices, should be a priority.

\section{Conclusion}

Over the last three decades, pharmacy education in Oman has evolved gradually, starting with a diplomagranting institute in 1991 to graduating PhD, albeit in a medical college. All pharmacy programmes are offered in a university. Two schools offer diplomas in pharmacy, and three schools graduate BSc. Graduate studies leading to MSc. in clinical pharmacy degree are provided by two universities; one of these (SQU) also offers a Ph.D. in clinical pharmacy. Undergraduate pharmacy programmes focus on traditional pharmacy education, such as fundamental and pharmaceutical sciences knowledge and skills. This educational system provides adequate healthcare services to the Omani community. However, more is expected from the pharmacist to enhance patient care and advance industrial pharmacy in Oman. Pharmacy schools should introduce OSCE as the standard method of assessment. They should work to sustain collaboration with policymakers, key stakeholders, and regulatory bodies to advance pharmacy education and the role of the pharmacy workforce in Oman. Ideally, such cooperation should start nationally and regionally. Pharmacy graduates in Oman have a great opportunity to excel by fulfilling their professional obligation and demonstrating to be highly competent healthcare professionals for better patient care.

\section{Conflict of interest}

The authors declare no conflict of interest.

\section{Source of funding}

The authors did not receive any funding. 


\section{References}

ACPE. (2021). International Services Programme. Accreditation Council For Pharmacy Education. Retrieved November 2021 from https://www.acpeaccredit.org/international-services-programme/

Ahmad, A., Alkharfy, K. M., Alrabiah, Z., \& Alhossan, A. (2020). Saudi Arabia, Pharmacists and Covid-19 Pandemic. Journal of Pharmaceutical Policy and Practice, 13(1), 1-3. https://doi.org/10.1186/s40545-020-00243-1

Al-Ghananeem, A. M., Malcom, D. R., Shammas, S., \& Aburjai, T. (2018). A Call to Action to Transform Pharmacy Education and Practice in the Arab World. American journal of pharmaceutical education, 82(9). https://doi.org/10.5688/ajpe7014

Alghamdi, E. A., Albalawi, O. M., \& Alshammari, T. M. (2021). Health Outcomes and Policy in Pharmacy Curricula among Arab Countries: An Evaluation of 191 Academic Institutions. Saudi Pharmaceutical Journal, 29(8), 799-806. https://doi.org/10.1016/j.jsps.2021.06.001

Aljadhey, H. (2013). Challenges Facing Advanced Pharmacy Practice Experience in Saudi Arabia. American journal of pharmaceutical education, 77(1). https://doi.org/10.5688/ajpe77119

Anderson, C., \& Futter, B. (2009). PharmD or Needs-Based Education: Which Comes First? American journal of pharmaceutical education, 73(5). https://doi.org/10.5688/aj730592

Chanakit, T., Low, B. Y., Wongpoowarak, P., Moolasarn, S., \& Anderson, C. (2014). A Survey of Pharmacy Education in Thailand. American journal of pharmaceutical education, 78(9). https://doi.org/10.5688/ajpe789161

Cokro, F., Atmanda, P. F. K., Sagala, R. J., Arrang, S. T., Notario, D., Rukmini, E., \& Aparasu, R. (2021). Pharmacy Education in Indonesia. Pharmacy Education, 21(1), 432 442. https://doi.org/10.46542/pe.2021.211.432442

DGPADC. (2019). Annual Report. Ministry of Health: Directorate General of Pharmaceutical Affairs \& Drug Control. Retrieved November 2020 from https://www.moh.gov.om/documents/16539/0/2019+Annu al+Report.pdf/52c0f748-7ac5-e12d-5eac-0fdd1ccc6c73

DGPADC. (2020). Requirements for Appearing Licensing Examination for Pharmacist and Assistant Pharmacists. . Ministry of Health Directorate General of Pharmaceutical Affairs and Drug Control. Retrieved November 2021 from https://www.moh.gov.om/documents/16539/0/reqq.pdf/c 4f3426f-c081-fc0f-2bf9-4104005f189e

El-Awaisi, A., Saffouh El Hajj, M., Joseph, S., \& Diack, L. (2016). Interprofessional Education in the Arabic-Speaking Middle East: Perspectives of Pharmacy Academics. Journal of interprofessional care, 30(6), 769-776. https://doi.org/10.1080/13561820.2016.1218830

El-Awaisi, A., Wilby, K. J., Wilbur, K., El Hajj, M. S., Awaisu, A., \& Paravattil, B. (2017). A Middle Eastern Journey of Integrating Interprofessional Education into the Healthcare Curriculum: A Swot Analysis. BMC medical education, 17(1) 1-10. https://doi.org/10.1186/s12909-016-0852-5
FIP. (2008). Pharmacy Education Taskforce: Action Plan 2008 - 2010. International Pharmaceutical Federation. Retrieved December 2021 from

https://www.fip.org/files/fip/PharmacyEducation/Taskforce \%20action\%20plan.pdf

FIP. (2014). Continuing Professional

Development/Continuing Education in Pharmacy: Global Report. International Pharmaceutical Federation. Retrieved December 2021 from https://www.fip.org/file/1407

FIP. (2020). The FIP Development Goals: Transforming Global Pharmacy. International Pharmaceutical Federation. Retrieved November 2021 from https://www.fip.org/file/4793

HEAC. (2021). Student Guidebook. Higher Education Admission Center.

https://heac.gov.om/media/doc/StudentGuid2021En.pdf

Kheir, N., Zaidan, M., Younes, H., El Hajj, M., Wilbur, K., \& Jewesson, P. J. (2008). Pharmacy Education and Practice in 13 Middle Eastern Countries. American journal of pharmaceutical education, 72(6).

https://doi.org/10.5688/aj7206133

Maidment, I., Young, E., MacPhee, M., Booth, A., Zaman, H., Breen, J., Hilton, A., Kelly, T., \& Wong, G. (2021). Rapid Realist Review of the Role of Community Pharmacy in the Public Health Response to Covid-19. BMJ Open, 11(6), e050043. https://doi.org/10.1136/bmjopen-2021-050043

MoH. (2014). Health Vision 2050: The Main Document. Oman: Ministry of Health.

https://www.moh.gov.om/documents/16506/119833/Healt h+Vision+2050

MoH. (2018). Annual Health Report Oman. Ministry of Health. Retrieved December 2020 from https://www.moh.gov.om/en_US/web/statistics/annualreports

MoH. (2020). Pharmacy Law: Ministerial Decree No. 113/2020 [Arabic]. Qanoon. Retrieved December 2021 from https://qanoon.om/p/2020/moh20200113/

Nasr, Z. G., \& Wilby, K. J. (2017). Introducing Problem-Based Learning into a Canadian-Accredited Middle Eastern Educational Setting. Currents in Pharmacy Teaching and Learning, 9(4), 719-722.

https://doi.org/10.1016/j.cptl.2017.03.027

NCSI. (2020). Statistical Year Book 2020:Issue 48. National Centre for Statistics and Information.

https://www.ncsi.gov.om/Elibrary/LibraryContentDoc/bar bar_2020_77577cb3-c8fe-49c6-ae5d-77f1fbae98e0.pdf

NUST. (2020). Bachelor of Pharmacy (B. Pharm). National University of Science and Technology. Retrieved December 2020 from

https://www.nu.edu.om/contentdetails.aspx?id=20

NUST. (2021). MSc in Clinical Pharmacy. National University of Science and Technology. Retrieved December 2021 from https://www.nu.edu.om/contentdetails.aspx?id=916

OAAA (2019). Oman Qualification Framework: Qualification Arrangements. Retrieved December 2021 from 
http://www.oaaa.gov.om/Journal/Qualification\%20Arrange ments.pdf

OAAA. (2020). Programme Accreditation. Oman Authority for Academic Accreditation and Quality Assurance of Education. Retrieved December 2021 from http://www.oaaa.gov.om/Default.aspx

Obaid, D., El-Dahiyat, F., \& Babar, Z.-U.-D. (2021). Recommendations to Improve Pharmacy Practice Research in the Middle Eastern Arab Countries. Journal of Pharmaceutical Policy and Practice, 14(1), 1-3. https://doi.org/10.1186/s40545-021-00357-0

OBG. (2015). The Report: Oman 2015. UK. Oxford Business Group. https://oxfordbusinessgroup.com/oman-2015

OMSB. (2021). Prometric Exam. Oman Medical Speciality Board. Retrieved November 2021 from https://www.prometric.com/test-takers/search/omsb

Resnik, D. B., Ranelli, P. L., \& Resnik, S. P. (2000). The Conflict between Ethics and Business in Community Pharmacy: What About Patient Counseling? Journal of Business Ethics, 28(2), 179-186.

https://doi.org/10.1023/A:1006280300427

SQU. (2020a). College of Medicine and Health Sciences: Pharmacology and Clinical Pharmacy. Sultan Qaboos University. Retrieved November 2021 from https://www.squ.edu.om/medicine/Departments/Pharmac ology-Clinical-Pharmacy/About-Pharmacology-ClinicalPharmacy

SQU. (2020b). Postgraduate Programme (2020/2021). Sultan Qaboos University. Retrieved November 2021. From https://www.squ.edu.om/Portals/42/xEvent/uploads/2020/ 6/18/programmes\%20AD\%2020-EN.pdf

SQU. (2021). Phd in Clinical Pharmacy. Sultan Qaboos University. Retrieved December 2021 from https://www.squ.edu.om/ps/enus/Programmes/ArticlelD/716/PhD-in-Clinical-Pharmacy

Supapaan, T., Low, B. Y., Wongpoowarak, P., Moolasarn, S., \& Anderson, C. (2019). A Transition from the Bpharm to the PharmD Degree in Five Selected Countries. Pharmacy Practice (Granada), 17(3).

https://doi.org/10.18549/PharmPract.2019.3.1611

UN. (2018a). Bachelor in Pharmacy Programme Outline. University of Nizwa. . Retrieved December 2020 from https://www.unizwa.edu.om/content_files/02375-4228.pdf

UN. (2018b). School of Pharmacy (Sop) Practicum and Internship Programme. University of Nizwa. Retrieved November 2020 from

https://www.unizwa.edu.om/index.php?contentid=2246

UN. (2020). School of Pharmacy: Department Profile. University of Nizwa. Retrieved Novmber 2019 from https://www.unizwa.edu.om/index.php?contentid $=2374$

UTAS. (2020). Pharmacy Department: Degree Audit. University of Technology and Applied Sciences, Higher College of Technology. Retrieved Novmber 2021 from https://www.hct.edu.om/pdf/pharmacy/degree-audit.pdf
Van Eekeren, R., Rolfes, L., Koster, A. S., Magro, L., Parthasarathi, G., Al Ramimmy, H., Schutte, T., Tanaka, D. van Puijenbroek, E., \& Härmark, L. (2018). What Future Healthcare Professionals Need to Know About Pharmacovigilance: Introduction of the WHO Pv Core Curriculum for University Teaching with Focus on Clinical Aspects. Drug safety, 41(11), 1003-1011. https://doi.org/10.1007/s40264-018-0681-z

WBG. (2019). Data: Oman. The World Bank Group. Retrieved November 2019 from https://data.worldbank.org/country/oman?view=chart

WHO. (2010). WHO Framework for Action on Interprofessional Education and Collaborative Practice. Geneva: World Health Organisation. http://apps.who.int/iris/bitstream/handle/10665/70185/W HO_HRH_HPN_10.3_eng.pdf 